\title{
Claval, Paul. Penser le monde en géographe. Soixant ans de réflexion. Paris: L'Harmattan. Collection Géographie et cultures, 2015, 247 p. ISBN 9782343070469
}

RESEÑA DE LIBRO

Paul Claval, profesor emérito de la Universidad de Paris IV-Sorbonne; consagra sus investigaciones a la historia y a la epistemología de la geografía, a la geografía económica, social y política, a la lógica de los sistemas territoriales y a los problemas culturales.

\section{Por Cristina Teresa Carballo}

Docente e investigadora del Departamento de Ciencias Sociales, Universidad Nacional de Quilmes, Argentina.

cristina.carballo@unq.edu.ar

Recibido: junio del 2016

Aceptado: agosto del 2016

PENSAR EL MUNDO COMO GEÓGRAFO. SESENTA AÑOS DE REFLEXIÓN, es una obra que proporciona ventajas tanto al público que ha seguido los aportes académicos de Paul Claval en la disciplina durante las últimas décadas, como también, y principalmente, a los cientistas sociales jóvenes que se inician en la investigación del mundo contemporáneo. Es decir, que indagan visiones del mundo y de la realidad social a partir de complejas redes socio-espaciales, sin olvidar a su interlocutor más preciado: el territorio.

Geografía, ciencia y constructo colectivo en la que resulta muy difícil comprender, en pocas líneas o páginas, el pasado reciente de la discusión geográfica como los debates del presente. En este escenario, adquiere relevancia la obra, y quizás sea uno de los principales legados de Paul Claval. Es una ruta, un camino biográfico de ideas y conceptos en Geografía que tuvieron su génesis desde la compulsa individual que motoriza la incertidumbre, desde el pensar en voz alta. Geógrafo -y geografía- que mira al Mundo desde una sucesión de preguntas, y no de certezas. Es decir, se concibe con humildad el rol del saber científico. Me atrevo a plantear que esta propuesta es en realidad una cartografía de ideas, un mapa particular y original. A la vez, nos posiciona en un cuadro de conceptos y teorías, experiencias y argumentos, que nos invita a "pensar" el mundo como un proceso incompleto e inacabado. 
El autor organiza su propuesta desde la discusión de algunos conceptos centrales del campo. Inicia su reflexión con la geografía clásica y el mundo de los años '50 cuya urbanización e industrialización se aceleran de tal manera que la ciencia social y geográfica lo aborda e interpela de forma imperfecta. El autor vuelve sobre la historia de la geografía para comprender el origen del malestar que esta atraviesa, y también se vuelca hacia la economía para reequilibrar una disciplina que dejaba de lado las circulaciones y los flujos. En los años '60 y '70 están aquellos que elaboran la Nueva Geografía y actualizan la geografía humana, social, económica, política y urbana. La disciplina atraviesa entonces una larga fase de cuestionamientos. Se construye sobre la mirada del geógrafo capaz, al mismo tiempo, de descifrar los problemas y descubrir las soluciones. Aunque, ignoraba las inquietudes, las dificultades, las aspiraciones y los sueños de aquellos a los que estudiaba. De esta manera, no se hacen esperar los nuevos planteos de la disciplina que dan cuenta de la diversidad de los hombres, de los problemas de identidad que ellos conocen y del sentido que ellos le dan a los paisajes y a los territorios en los cuales viven; para Claval, es el giro cultural que lleva a la disciplina a un análisis profundo de las realidades humanas.

Tomemos una distancia prudencial de los aportes del autor, y podremos tener un panorama completo de las evoluciones de la disciplina hasta la geografía actual. Poder sumergirnos en el texto es iluminar, desde otras miradas, los desafíos a los cuales la humanidad está confrontada, a la vez, que es explorar los cambios de actitud que ella, la ciencia geográfica, debe efectuar sin perder de vista la dinámica del presente. Es imaginar las nuevas herramientas de las cuales debe dotarse. Es participar en la refundación del pacto que une a los hombres y al planeta que los hace vivir. "Mon intérêt pour la géographie n'a jamais été limité aux travaux académiques: je me suis toujours soucié de l'ensembre des pratiques et des réflexions que les groupes humains ont consacrées, et consacrent, à l'espace" Esta frase expresa la esencia de la obra. Quizás el título en español más próximo al sentido genuino de Paul Claval y de su lengua original, sería: Pensar el mundo desde la mirada de un geógrafo... Como siempre, el lector tendrá la última palabra. 